\title{
AVALIAÇÃO IN VITRO DA AÇÃO DE ACARICIDAS SOBRE Rhipicephalus (Boophilus) microplus CANESTRINI, 1887 (ACARI: IXODIDAE) DE BOVINOS LEITEIROS NO MUNICÍPIO DE ITAMARAJU, BAHIA, BRASIL
}

\author{
Fernando Henrique Spagnol, ${ }^{1}$ Elisson Barroso Paranhos² E George Rego Albuquerque ${ }^{3}$ \\ 1. Discente do Programa de Pós-Graduação em Ciência Animal, UESC. Bolsista FAPESB \\ 2. Discente do curso de Medicina Veterinária. Bolsista PIBIC/CNPq/UESC \\ 3. Professor adjunto do Departamento de Ciências Agrárias e Ambientais-UESC. Área de parasitologia veterinária e doenças parasitárias. \\ E-mail: gralbu@uesc.br.
}

\section{RESUMO}

Diante da suspeita de que diversas populações de $R$. microplus estejam resistentes a carrapaticidas no município de Itamaraju, realizou-se avaliação in vitro, no período de janeiro a novembro de 2008, pela técnica de biocarrapatocidograma, dos nove acaricidas mais comercializados no município, utilizando-se carrapatos de 22 propriedades leiteiras. A média da eficiência do fipronil foi de $99 \%$, do clorpirifós + cipermetrina high-cis de $92 \%$, da amitraz+clorpirifós de $90,7 \%$, do diclorvós+clorpirifós de $81,4 \%$, do cipermetrina+clorpirifós+citronelol de 49,2\%, da amitraz de $49,0 \%$, do cipermetrina + ethion de $39,9 \%$, do deltametrina de $33,9 \%$ e do cipermetrina de $21,1 \%$. Houve uma variação de um a cinco carrapaticidas eficazes ( $\geq 95 \%$ ) por propriedade. Os resultados denotam um uso equivocado dos acaricidas pelos produtores e com isso um alto grau de resistência pelos carrapatos.

PALAVRAS-CHAVES: Bovinos, carrapaticidas, carrapatos, resistência.

\section{ABSTRACT}

IN VITRO EVALUATION OF ACARICIDES ON Rhipicephalus (Boophilus) microplus CANESTRINI, 1887 (ACARI: IXODIDAE) OF DAIRY CATTLE IN ITAMARAJU MUNICIPALITY, BAHIA, BRAZIL

As many tick populations of Rhipicephalus (Boophilus) microplus can be resistant to drugs in the municipality of Itamaraju, Bahia, Brazil, an in vitro immersion test was carried out, from January to November 2008, in ticks from 22 dairy farms using the nine most used acaricides in the market. Fipronil had 99\% efficacy, Chlorpyriphos + Cypermethrin high-cis $92 \%$, Amitraz + Chlorpyriphos

KEYWORDS: Cattle, resistance, tickcides, ticks.

\section{INTRODUÇÃO}

Rhipicephalus (Boophilus) microplus é um dos principais parasitos de bovinos, causador de grandes prejuízos à bovinocultura nacional, evidenciados pela perda
90.7\%, Diclorvos+Chlorpyriphos 81.4\%, Cypermethrin+Chlorpy riphos+Citronelol 49.2\%, Amitraz 49.0\%, Cypermethrin+Ethion $39.9 \%$, Deltamethrin $33.9 \%$, Cypermethrin $21.1 \%$. There was a range from one to five efficient acaricides ( $\geq 95 \%$ ) in each property. The results show that there is a wrong use of acaricides by the farmers and a high degree of resistance by ticks.

na produção de leite e carne, anemia, lesões que afetam a qualidade do couro e transmissão de agentes infecciosos, principalmente Anaplasma e Babesia, responsáveis pela tristeza parasitária bovina (TPB) (GOMES, 1998; JONGEJAN \& UILENBERG, 2004; JOHSSON, 2006). 
Além dos prejuízos diretos, existem os indiretos, causados pelo incremento nos gastos com a mão de obra necessária para o seu combate, que varia conforme a intensidade da infestação e com a frequência dos tratamentos carrapaticidas (ROCHA, 1996), além da necessidade de instalações e equipamento apropriados para o tratamento dos bovinos e aquisição dos carrapaticidas (MARTINS et al., 2006).

O controle do $R$. (B.) microplus se baseia quase que exclusivamente na utilização de produtos químicos, principalmente de contato. Atualmente os grupos químicos encontrados no mercado na formulação de carrapaticidas de contato são os organofosforados, amidínicos, piretroides, fenilpirazois e naturalyte, e o quadro do controle químico para carrapatos se caracteriza por um aumento cada vez maior do número de cepas resistentes aos principais acaricidas utilizados (FURLONG et al., 2007).

A resistência do $R$. (B.) microplus aos carrapaticidas tem sido relatada nas diferentes regiões do Brasil (ARANTES et al., 1995; SILVA et al., 2000; SANTANA et al., 2001; CAMPOS JUNIOR \& OLIVEIRA, 2005; PEREIRA, 2006; CAMILLO et al., 2009).

O município de Itamaraju é localizado no extremo sul do Estado da Bahia, com clima tropical úmido, temperatura média anual de $24^{\circ} \mathrm{C}$, baixa amplitude térmica (entre $18^{\circ} \mathrm{C}$ e $30^{\circ} \mathrm{C}$ ) e elevado índice pluviométrico $(1.600 \mathrm{~mm} / \mathrm{ano})$, favorecendo o desenvolvimento do $R$. (B.) microplus durante todos os meses do ano. Possui o maior rebanho bovino do Estado, com 173.584 animais, sendo 19.218 vacas leiteiras predominantemente mestiças (IBGE, 2005). A hipótese de que os carrapatos das propriedades leiteiras do município já estejam resistentes a diversos carrapaticidas, dado o uso intenso e desordenado destes, objetivou-se com este trabalho avaliar a eficácia in vitro de acaricidas comerciais sobre fêmeas ingurgitadas de $R$. microplus oriundos de bovinos leiteiros de Itamaraju, Bahia.

\section{MATERIAL E MÉTODOS}

O estudo foi desenvolvido no município de Itamaraju (altitude entre 40 e $200 \mathrm{~m}$; latitude Sul 17 $02^{\circ}$ ' e longitude Oeste $39^{\circ} 31^{\prime}$ e área de $2.370 \mathrm{~km}^{2}$ ), localizado na Mesorregião do Sul Baiano e Microrregião de Porto Seguro, no Estado da Bahia (IBGE, 2005).
No período de janeiro a novembro de 2008 , foram avaliados os nove carrapaticidas mais comercializados no município, após pesquisa nas principais casas agropecuárias, em 22 propriedades leiteiras. Os produtos foram: 1) associação de amitraz $50 \%$ e clorpirifós $50 \%$; 2) associação de clorpirifós $50 \%$ e cipermetrina high cis $6 \%$; 3 ) associação de ethion $60 \%$ e cipermetrina $8 \%$; 4) amitraz $12,5 \%$; 5) cipermetrina $15 \%$; 6) associação de diclorvós $60 \%$ e clorpirifós $20 \%$; 7 ) associação cipermetrina $15 \%$, clorpirifós $25 \%$ e citronelal; 8 ) deltametrina $2,5 \%$; 9) fipronil $1 \%$. Para realização dos testes, os carrapaticidas foram diluídos em água destilada conforme recomendação dos fabricantes.

A escolha das propriedades foi por conveniência, considerando-se os produtores que se propuseram a participar. Em cada propriedade, houve aplicação de um questionário ao funcionário responsável pelo manejo do gado ou ao proprietário, para avaliar o uso dos carrapaticidas e verificar as características das propriedades.

Coletaram-se aproximadamente 200 fêmeas ingurgitadas por propriedade. As teleóginas foram retiradas de vacas que não haviam recebido banho carrapaticida por no mínimo 25 dias ou 45 dias quando usavam produtos sistêmicos. Acondicionaram-se os carrapatos em frasco de vidro com perfuração na tampa para oxigenação, sendo remetidos no mesmo dia ao Laboratório de Parasitologia Veterinária da Universidade Estadual de Santa Cruz, para realização dos testes in vitro.

Para a realização dos testes de sensibilidade, seguiu-se a técnica de DRUMMOND et al. (1973), modificada no que se refere ao tempo de imersão, alterado de três para cinco minutos. Foram utilizadas, para os testes, apenas teleóginas coletadas nas últimas 48 horas, em perfeito estado físico, sem alterações morfológicas ou restos de tegumento no aparelho bucal.

No laboratório, as teleóginas foram lavadas com uso de peneira em água corrente, secas com papel absorvente e pesadas em balança analítica para formação de grupos homogêneos de dez espécimes, sendo que se contituiu o número de grupos igual ao número de produtos testados mais dois grupos-controles.

Em seguida, os grupos foram imersos durante cinco minutos em recipientes plásticos identificados, contendo as diluições em água destilada recomendadas pelos fabricantes de cada acaricida de contato testado, além dos grupos-controle imersos apenas em água des- 
tilada. Para o fipronil, preparou-se a diluição também conforme orientações do fabricante, porém em uma solução contendo $40 \%$ de acetona e $60 \%$ de água destilada (JOHN FURLONG - comunicação pessoal).

Após este período, foram secas em papel absorvente e acondicionadas em placas de Petri devidamente identificadas e levadas à estufa tipo BOD, à temperatura de $27^{\circ} \mathrm{C} \pm 1{ }^{\circ} \mathrm{C}$ e umidade relativa do ar de $85 \%$ $\pm 5 \%$. Após a postura, a massa de ovos foi pesada, transferida para uma seringa cortada na extremidade $\mathrm{e}$ lacrada com algodão e levada novamente à estufa BOD para posterior avaliação da eclodibilidade.

As principais variáveis da pesquisa foram registradas em formulário próprio contendo peso das posturas ( $15^{\circ}$ dia de postura), percentual de eclodibilidade ( $25^{\circ}$ dia após a pesagem das massas de ovos) e eficiência do produto (EP). Observaram-se os valores para cada lote testado, além do grupo-controle. A avaliação das variáveis foi realizada segundo as equações prescritas por DRUMMOND et al. (1973):

$$
\begin{aligned}
\mathrm{ER}^{*} & =\underset{\text { peso dos ovos } \mathrm{x} \% \text { eclosão x } 20.000^{* *}}{\text { peso das teleóginas }}
\end{aligned}
$$

* Eficiência reprodutiva;

**A constante 20.000 significa o número estimado de ovos em $1 \mathrm{~g}$ de ovos de Rhipicephalus (Boophilus) microplus.

\section{EP*= ER grupo controle-ER grupo tratado $\mathrm{x} 100$ ER do grupo-controle}

Realizou-se análise estatística dos resultados, utilizando-se o GraphPad InStat 3.06 Demo, através do teste de Kruskal-Wallis, para a comparação das médias das eficiências dos compostos carrapaticidas testados, com significância de 5\%(p>0,05).

\section{RESULTADOS E DISCUSSÃO}

Em análise dos questionários, verificou-se que apenas $23 \%$ das propriedades possuía manejo semiintensivo; nas demais (77\%), o manejo era extensivo. A maioria das propriedades $(91 \%)$ tinha tronco de manejo, porém $91 \%$ delas faziam uso de bomba costal na pulverização. Desse modo, $82 \%$ das propriedades utilizavam volume de calda abaixo dos quatro a cinco litros por animal, pela dificuldade do funcionário em sustentar um pulverizador de quase $30 \mathrm{~kg}$, facilitando a instalação da resistência. Tal problema seria amenizado com uso da bomba de pulverização elétrica. Porém, apenas $9 \%$ das propriedades faziam uso desse equipamento. Além disso, nenhuma propriedade realizava controle estratégico. Afora isso, $50 \%$ das propriedades faziam banho dos animais com carrapaticidas em intervalos inferiores a 21 dias, ocasionando um aumento na pressão de seleção.

SANTANA et al. (2001) verificaram que o mau uso do carrapaticida na região da zona da mata e agreste de Pernambuco era um dos principais fatores predisponentes para a resistência dos carrapatos aos carrapaticidas na região. SANTOS et al. (2009) concluem que o número de aplicações de carrapaticidas igual ou maior que quatro ao ano é um importante fator de risco para seleção de populações de carrapatos difíceis de serem controlados com carrapaticidas. A ocorrência de tais fatores de risco desequilibra o conjunto de componentes para combate dos carrapatos, quais sejam: produto certo, dosagem correta, momento exato e remoção de uma proporção adequada da população de parasitos (ARANTES, 1995). Assim, a falta de pelo menos um destes acarreta ameaça a todo o sistema de controle e, consequentemente, favorece seleção para resistência.

Quanto à avaliação dos carrapaticidas, observou-se que o fipronil foi o de maior eficiência e a cipermetrina o pior (Tabela 1). Denota-se alto grau de resistência aos carrapaticidas, considerando que o recomendável seriam produtos com eficiência igual ou superior a $95 \%$ para que o produto fosse considerado eficaz, com base nas exigências do Ministério da Agricultura Pecuária e Abastecimento (MAPA, 1987). Esses resultados são semelhantes aos obtidos por FURLONG et al. (2007), que avaliaram populações de carrapatos oriundas de todas as regiões do Brasil no período de 1997 a 2006, com exceção da cipermetrina+clorpirifó $\mathrm{s}+$ citronelal, que apresentava uma eficácia menor em Itamaraju, possivelmente por ser o carrapaticida mais utilizado nas propriedades avaliadas (13/22).

Houve uma grande variação na eficiência dos acaricidas testados nas diferentes propriedades, principalmente pelo manejo diferenciado em cada fazenda e diversidade de produtos já utilizados, o que pode ser evidenciado pelo resultado alto dos desviospadrões, principalmente dos seguintes produtos: clorpirifós +cipermetrina high-cis; amitraz+clorpirifós; diclorvós+clorpirifós, que estão dentro de uma mesma categoria de classificação estatística (a). 
TABELA 1. Eficiência in vitro dos nove carrapaticidas testados sobre as 22 populações de Rhipicephalus (Boophilus) microplus coletados no município de Itamaraju, Bahia

\begin{tabular}{llcccc}
\hline \multirow{2}{*}{ Princípio ativo } & Grupo químico & \multicolumn{3}{c}{ Eficácia(\%) } \\
\cline { 3 - 5 } & & Mín. & Máx. & Média* & $\begin{array}{c}\text { Desvio- } \\
\text { padrão }\end{array}$ \\
\hline Fipronil & Fenilpirazol & 90,8 & 100 & $99,00^{\text {a }}$ & 2,5 \\
Clorpirifós+cipermetrina high-CIS & Organofosforado+piretroide & 44,2 & 100 & $92,10^{\text {a }}$ & 16,71 \\
Amitraz+clorpirifós & Formamidina+organofosforado & 17,6 & 100 & $90,70^{\text {a }}$ & 18,78 \\
Diclorvós+clorpirifós & Organofosforado+organofosforado & 0 & 100 & $81,40^{\text {ab }}$ & 23,23 \\
Cipermetrina+clorpirifós+citronelol & Piretroide+organofosforado+repelente & 0 & 97,6 & $49,20^{\text {bc }}$ & 31,37 \\
Amitraz & Formamidina & 0 & 100 & $49,00^{\text {bc }}$ & 27,22 \\
Ethion+cipermetrina & Organofosforado+piretroide & 0 & 81,4 & $39,90^{\text {c }}$ & 25,33 \\
Deltametrina & Piretroide & 0 & 90,9 & $33,90^{\text {c }}$ & 24,38 \\
Cipermetrina & Piretroide & 0 & 78,7 & $21,10^{\text {c }}$ & 22,03 \\
\hline
\end{tabular}

*Médias com letras iguais não diferem entre si $(\mathrm{P}>0,05)$.

O número de acaricidas eficazes ( $\mathrm{EP} \geq 95 \%)$ para cada uma das 22 propriedades estudadas variou de um a cinco. Os melhores resultados foram obtidos pelo fipronil, com 90,9\% das propriedades apresentando eficiência superior a 95\% (Tabela 2). Esses resultados corroboram os de CAMPOS JR. \& OLIVEIRA (2005), que estudaram a eficiência de carrapaticidas na mircrorregião de Ilhéus-Itabuna, Bahia, e encontraram apenas $6,7 \%$ de propriedades com eficácia $(\mathrm{EP} \geq 95 \%$ ) para o amitraz e $10 \%$ para a deltametrina.

TABELA 2. Percentual de propriedades, dentre as 22 avaliadas no município de Itamaraju, Bahia, em que os produtos testados se mostraram eficazes $(\mathrm{EP} \geq 95 \%)$

\begin{tabular}{lc}
\hline \multicolumn{1}{c}{ Produtos } & $\begin{array}{c}\text { Eficácia em proprie- } \\
\text { dades }(\%)\end{array}$ \\
\hline Fipronil & $90,90 \%$ \\
Clorpirifós+Cipermetrina high cis & $77,30 \%$ \\
Amitraz+clorpirifós & $69,20 \%$ \\
Diclorvós+clorpirifós & $36,40 \%$ \\
Cipermetrina+clorpirifós+citronelal & $13,60 \%$ \\
Amitraz & $4,50 \%$ \\
Ethion+cipermetrina & 0 \\
Deltametrina & 0 \\
Cipermetrina & 0 \\
\hline
\end{tabular}

O desempenho do fipronil com $99 \%$ de eficácia observado neste estudo foi superior ao observado por
FURLONG et al. (2007). Tal resultado pode ser explicado pelo uso limitado a poucas propriedades $(2 / 22)$, possivelmente em função do preço, ou por ser um produto de uso proibido em vacas lactentes.

A associação de amitraz e clorpirifós (90,7\%) também apresentou bons resultados no Rio Grande do Sul (CAMILLO et al., 2009), onde foi obtida eficiência de $100 \%$ em onze propriedades avaliadas, mostrando um bom desempenho do efeito sinérgico na associação de amidínicos e fosforados em regiões distintas.

Amelhor eficiência das associações de piretroides e organofosforados com o uso dos princípios ativos isolados foi descrita por diversos autores (CAMPOS JR. \& OLIVEIRA, 2005; PEREIRA, 2006; FURLONG et al., 2007; FARIAS et al., 2008; SANTOS et al., 2008; CAMILLO et al., 2009), provavelmente pelo fato de os grupos químicos possuírem mecanismos de ação diferentes e atuarem em sítios bioquímicos distintos, o que leva a um maior efeito na utilização de ambos, quando combinados.

Os resultados dos trabalhos utilizando o amitraz foram contraditórios. A baixa eficiência obtida em Itamaraju (49\%) também foi verificada nos estudos de CAMPOS JR. \& OLIVEIRA (2005), PEREIRA (2006), FURLONG et al. (2007) e CAMILLO et al. (2009). Porém, trata-se de resultados que são diferentes dos obtidos por FERREZINI et al. (2007), com 99\%, e SANTOS et al. (2008), com 94\% de eficiência. Esse contraste pode ser explicado pela frequência de uso do amitraz nas várias regiões do Brasil, aliado à possível 
reversão da resistência às amidinas, após quinze a vinte gerações de carrapatos sem utilização desse produto.

Os piores desempenhos obtidos foram para produtos do grupo químico dos piretroides utilizados isoladamente (deltametrina 33,9\%; cipermetrina 21,1\%), resultado que se assemelha diversos estudos no país (SILVA et al., 2000; SOUZA et al., 2003; PEREIRA, 2006; FERREZINI et al., 2007; FURLONG et al., 2007; FARIAS et al., 2008; SANTOS et al., 2008), possivelmente pela característica de maior poder residual, que favorece a sobrevivência de indivíduos naturalmente tolerantes, além do fato de possuir resistência cruzada com os organoclorados (FURLONG et al., 2007), facilitando o desenvolvimento da resistência nas populações de carrapatos.

Quando comparados os resultados dos piretroides com os amidínicos, percebe-se claramente que, apesar do uso de ambos ao longo dos anos em todo o país, a característica de reversibilidade da resistência (FURLONG et al. 2007) possibilita ainda, às amidinas, desempenho satisfatório em muitas regiões do país, o que não ocorre com os piretroides, que, apesar de serem produtos mais recentes, não possuem tal característica.

O preço dos carrapaticidas foi pré-requisito primordial na escolha do produto pelo pecuarista; o segundo foi a eficácia dele. A comparação do preço com a eficácia dos produtos está ilustrada na Figura 1. É possível notar a mesma tendência das duas linhas, confirmando-se a suspeita de que os produtores utilizam produtos mais baratos com maior intensidade que os mais caros, acarretando, assim, a instalação da resistência inicialmente neles.

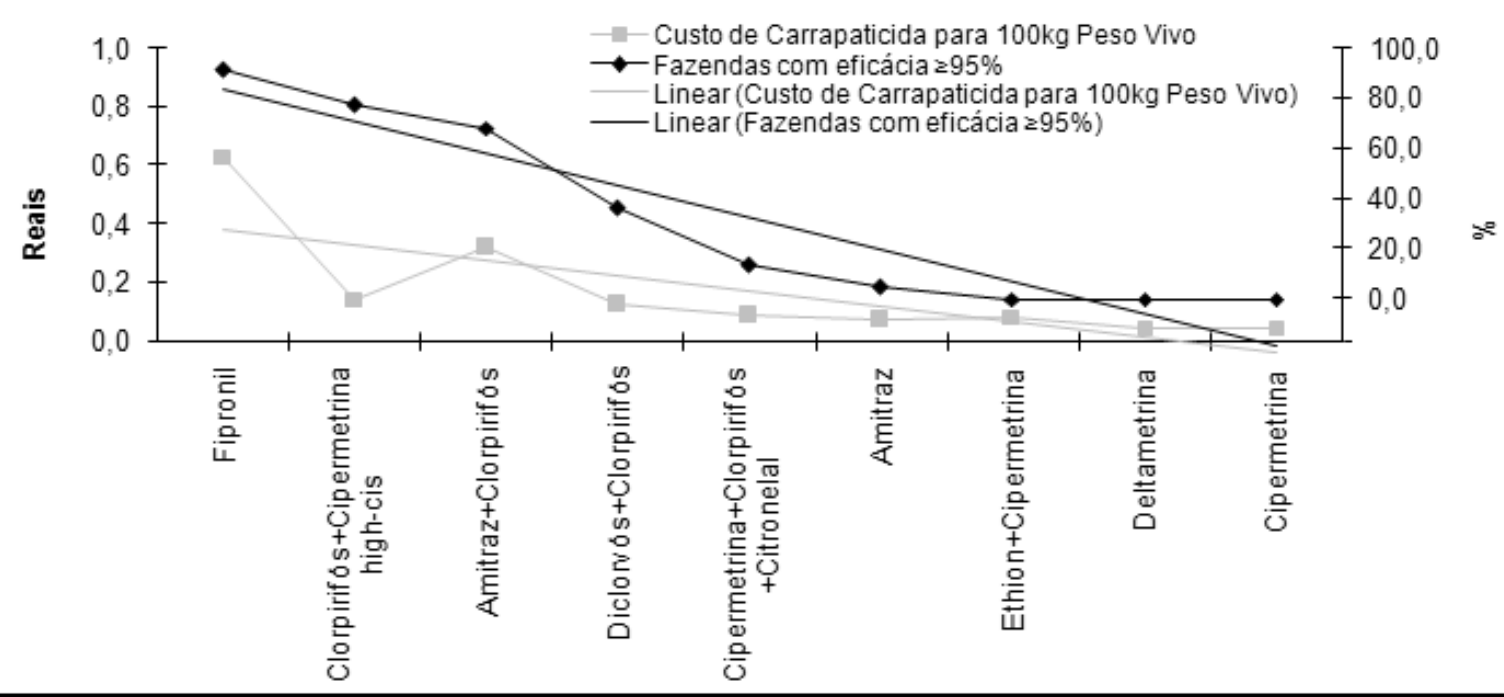

FIGURA 1. Tendência linear do custo do carrapaticida e o percentual de propriedades que apresentam eficácia $\geq 95 \%$ aos carrapaticidas testados em Itamaraju, BA.

\section{CONCLUSÕES}

A resistência dos carrapatos aos carrapaticidas ocorre nas propriedades leiteiras testadas do município de Itamaraju. Apenas um produto (felilpirazol - fipronil), dos nove testados, obteve resultados acima da eficiência recomendada de $95 \%$. Os produtores rurais realizam, em sua maioria, o manejo dos carrapaticidas de forma errada, o que pode estar acelerando o aparecimento da resistência.

\section{REFERÊNCIAS}

ARANTES, G. J.; MARQUES, A. O.; HONER, M. R. O carrapato do bovino, Boophilus microplus, no município de Uberlândia, MG: análise da sua resistência contra carrapaticidas comerciais. 
Revista Brasileira de Parasitologia Veterinária, v. 4, n. 2, p. 89-93, 1995.

BECHARA, G. H. Carrapatos de importância médico-veterinária da região neotropical: um guia ilustrado para identificação de espécies. São Paulo: Editora Vox/ICTTD-3/Butantan, 2006. 9, p. $145-152$.

CAMILLO, G.; VOGEL, F. F.; SANGIONI, L. A.; CADORE, G. C.; FERRARI, R. Eficiência in vitro de acaricidas sobre carrapatos de bovinos no Estado do Rio Grande do Sul, Brasil. Ciência Rural, v. 39, n. 2, p. 490-495, 2009.

CAMPOS JR. D. A.; OLIVEIRA, R. R. Avaliação in vitro da eficácia de acaricidas sobre Boophilus microplus (Canestrini, 1887) (Acari:Ixodidae) de bovinos do município de Ilhéus, Bahia, Brasil. Ciência Rural, v. 35, n. 6, p. 1386-1392, 2005.

DRUMMOND, R. O.; ERNST, S. E.; TREVINO, J. L.; GLADNEY, W. J.; GRAHAM, O. H. Boophilus annulatus and Boophilus microplus: laboratory tests for insecticides. Journal of Economic Entomology, v. 66, p. 130-133, 1973.

FARIAS, N. A.; RUAS, J. L.; SANTOS, T. R. B. Análise da eficácia de acaricidas sobre o carrapato Boophilus microplus, durante a última década, na região sul do Rio Grande do Sul. Ciência Rural, v. 38, n. 6, p. 1700-1704, 2008.

FERREZINI, J. ; SCHIAVONE, D. ; BRITO, L. G.; OLIVEIRA, M. C. S. ; CHAGAS, A. C. S. Diagnóstico da resistência de Rhipicephalus Boophilus microplus a carrapaticidas no rebanho bovino da Embrapa Pecuária Sudeste. In: SIMPÓSIO DE INICIAÇÃO CIENTÍFICADA EMBRAPAPECUÁRIA SUDESTE, 2., 2007, São Carlos, SP. Anais... São Carlos: Embrapa Pecuária Sudeste, 2007. p. 27.

FURLONG, J.; MARTINS, J. R.; PRATA, M. C. A. O carrapato dos bovinos e a resistência: temos o que comemorar? Hora Veterinária, n. 159, p. 1-7, 2007.

GOMES, A. O carrapato-do-boi Boophilus microplus: ciclo, biologia, epidemiologia, patogenia e controle. In: KESSLER, R. H.; SCHENK, M. A. M. Carrapato, tristeza parasitária e tripanossomíase dos bovinos. Campo Grande: EMBRAPA-GNPGC, 1998. p. 9-44.

IBGE - Instituto Brasileiro de Geografia e Estatística, Ministério do Planejamento Orçamento e Gestão. Disponível em: <www. ibge.gov.br/home/estatistica/economia/ppm/2005/default.shtm> Acesso em: 3 abr. 2007.

JOHSSON, N. N. The productivity effects of cattle tick (Boophilus microplus) infestation on cattle, with particular reference to Bos indicus cattle and their crosses. Veterinary Parasitology, v. 137, n. 1-10, 2006.
JONGEJAN, F.; UILENGERG, G. The global importance of ticks. Parasitology, n. 129, s3-s14, 2004.

MARTINS, J. R. S.; FURLONG, J.; LEITE, R. C. Controle de carrapatos: carrapatos de importância médico-veterinária da Região Neotropical. São Paulo: Editora Vox/ICTTD-3/Butantan, p. $145-152,2006$

MAPA - Ministério da Agricultura. Normas para registros de parasiticidas de uso pecuário na Brasil. Brasília: Ministério da Agricultura, 1987. 19 p. (Mimeografado).

PEREIRA, J. R. Eficácia in vitro de formulações comerciais de carrapaticidas em teleóginas de Boophilus microplus coletadas de bovinos leiteiros do Vale do Paraíba, Estado de São Paulo. Revista Brasileira de Parasitologia Veterinária, v. 15, n. 2, p. 45-48, 2006.

ROCHA, C. M. B. M. Caracterização da percepção dos produtores do município de Divinópolis/MG sobre a importância do carrapato Boophilus microplus e fatores determinantes das formas de combate utilizadas. 1996. $70 \mathrm{f}$. Dissertação (Mestrado em Medicina Veterinária) - Curso de Pós-Graduação em Medicina Veterinária, Universidade Federal de Minas Gerais, 1996.

SANTANA, V. L. A.; FAUSTINO, M. A. G.; FURLONG, J.; LIMA, M. M.; ALVES, L. C. Diagnóstico de situação do controle químico do carrapato dos bovinos (Boophilus microplus) em propriedades das mesorregiões da mata e agreste do Estado de Pernambuco - Brasil. Ciência Veterinária nos Trópicos, v. 4, n. 2-3, p. 281-290, 2001.

SANTOS, T. R.; FARIAS, N. A.; CUNHA FILHO, N. A.; PAPPEN, F. G.; VAZ JUNIOR, I. S. Abordagem sobre o controle do carrapato Rhipicephalus (Boophilus) microplus no sul do Rio Grande do Sul. Pesquisa Veterinária Brasileira, v. 28, n. 1, p. 65-70, 2009.

SANTOS, T. R. B.; FARIAS, N. A. R.; CUNHA FILHO, N. A.; VAZ JÚNIOR, I. S. Uso de acaricidas em Rhipicephalus (Boophilus) microplus de duas regiões fisiográficas do Rio Grande do Sul. Acta Scientiae Veterinarie, v. 36, n. 1, p. 25-30, 2008.

SILVA, M. C. L.; SOBRINHO, R. N.; LINHARES, G. F. C. Avaliação in vitro da eficácia do Clorfenvifós e da Cialotrina sobre o Boophilus microplus, colhidos em bovinos da bacia leiteira da microrregião de Goiânia-Goiás. Ciência Animal Brasileira, v. 1, n. 2 , p. $143-148,2000$.

SOUZA, A. P.; SARTOR, A. A.; BELLATO, V.; PERUSSOLO, S. Eficácia de carrapaticidas em rebanhos de bovinos leiteiros de municípios da Região Centro Sul do Paraná. Revista de Ciências Agroveterinárias, v. 2, n. 2, p. 131-135, 2003. 